\title{
Evaluation of Economics in Different Rice Varieties for Organic Farming
}

\author{
Khemraj Dubey ${ }^{1}$, V.K. Shukla ${ }^{1}$, Gajendra Raghuvansi ${ }^{2}$, \\ S.K. Vishwakarma ${ }^{1}$ and Muni Pratap Sahu ${ }^{*}$ \\ ${ }^{1}$ Jawaharlala Nehru Krishi Vishwa Vidhyalaya, Jabalpur (M.P.), India \\ ${ }^{2} \mathrm{JNKVV}, \mathrm{COA}$, Tikamgarh (MP), India \\ *Corresponding author
}

A B S T R A C T

\begin{tabular}{|l|}
\hline Ke y w o r d s \\
Gross monitoring \\
return, Net \\
monitoring return, \\
B:C ratio, Rice \\
variety
\end{tabular}

\begin{abstract}
A field experiment entitled "Evaluation of Rice Varieties for Organic Farming" was undertaken at Krishi Nagar Farm, JNKVV, Jabalpur (Madhya Pradesh) during Kharif season of 2015. The experiment was laid out in "randomized block design" with three replications. Twelve varieties of rice viz. T1 (PS 5), T2 (Sahyadri), T3 (PS 4), T4 (BVD 109), T5 (JR 201), T6 (Danteshwari), T7 (Madhumati), T8 (IR 36), T9 (MTU 1010), T10 (IR 64), T11 (Pusa Basmati 1) and T12 (PS 3) were grown under organic nutrient management (A uniform dose of organic manures i.e. 1/3rd $\mathrm{N}$ through each of FYM, Neemcake and Vermicompost and rock phosphate were applied to all varieties).Among the varieties both grain and straw yields significantly differed. Variety PS 3 excelled to all for grain yields $(3525 \mathrm{~kg} / \mathrm{ha})$ and Variety BVD 109 was the lowest yielder $(2563 \mathrm{~kg} / \mathrm{ha})$. As regards straw yields, again PS 3 was top yielder $(5336 \mathrm{~kg} / \mathrm{ha})$ while IR 36 was the lowest yielder (4676 kg/ha). The economic viability among all the treatment the cost of cultivation was different for scented and non-scented varieties because of higher price of scented seeds. While considering the gross monitoring return(GMR), variety PS 3 fetched the highest (Rs111086/ha) value due to higher seed and stover yields. The gross monitoring return(GMR) was minimum with BVD 109 (Rs 56499/ha). As regards the net monitoring return(NMR), variety PS 3 fetched the highest value (Rs 67168/ha) this treatment was markedly higher than rest of the treatments. The profitability was maximum with PS 3 (2.53).
\end{abstract}

\section{Introduction}

Rice (Oryza sativa L.) is the most important food crop of India in terms of both area and production and consumer preference. India is the $2^{\text {nd }}$ largest producer and consumer of rice in the world. Rice is the staple food crop for more than $65 \%$ population globally and provides $60-70 \%$ body calorie intake to the consumer. The total area under organic certification is 4.72 million hectare. India produced around 1.24 million tone of certified organic products which include 0.0492 million tone (Basmati rice 4\%). In India, among all the states, Madhya Pradesh has covered largest area under organic certification followed by Himachal Pradesh and Rajasthan (Anonymous, 2014). 
Intensive agriculture, escalading prices of chemical fertilizers and reduction in the availability of organic manures day by day, demands integrated use of organic manures and chemical fertilizers for maintaining soil health and attaining sustainable crop production. As the organic sources of nutrients are mostly drawn from local resources and developed locally viz. FYM, vermicompost, neemcake and crop residues etc. which are cheap and easy to manipulate. Vermicompost being a rich source of macro and micro nutrients, vitamins, plant growth regulators and beneficial microflora, appeared to be the best organic source in maintaining soil fertility on sustainable basis towards an eco-friendly environment. Therefore, this approach enhances the economical way of crop production by reducing the cost of cultivation and increasing the market value of produce. Kumar et al., (2007) recorded higher yield of rice and wheat with the use of organic manures. Kymore Plateau and Satpura hill zone comes under rice growing tract. Cultivation of rice-wheat and rice-gram are not economical due to higher cost of cultivation. Under organic farming package, there is possibility to grow scented rice due to high demand of organic production.

\section{Materials and Methods}

The present investigation entitled "Evaluation of Rice Varieties for Organic Farming" was conducted during Kharif season of 2015. The materials used and methodologies employed to conduct the field experiment at Krishi Nagar, Research Farm, Jawaharlal Nehru Krishi Vishwa Vidyalaya, Jabalpur (MP) during kharif season 2015. The treatments comprised twelve varieties of rice viz. T1 (PS 5), T2 (Sahyadri), T3 (PS 4), T4 (BVD 109), T5 (JR 201), T6 (Danteshwari), T7 (Madhumati), T8 (IR 36), T9 (MTU 1010), T10 (IR 64), T11 (Pusa Basmati 1) and T12 (PS 3) were grown under organic nutrient management (A uniform dose of organic manures i.e. 1/3rd $\mathrm{N}$ through each of FYM, Neemcake and Vermicompost and rock phosphate were applied to all varieties).The experiment was conducted Adequate research facilities viz. irrigation water, seeds, organic manures and equipment's etc. were available on the research farm to conduct the research work. Jabalpur is situated in the central part of Madhya Pradesh at 23091' North latitude, 79058' East longitudes with an average altitude of 411.78 meters above the mean sea level. The soil of the experimental field at initial stage was sandy clay loam, neutral in reaction $(\mathrm{pH} 7.25)$ with medium OC $(0.71 \%)$ contents, normal in EC (0.34) and analyzing low in available $\mathrm{N}(272.83 \mathrm{~kg} / \mathrm{ha})$, medium in available $\mathrm{P}(13.72 \mathrm{~kg} / \mathrm{ha})$ and medium in available K (294.75 kg/ha) contents. As a whole, the soil properties of the field are representative for the soils existing in major parts of the rice growing belts of the region.

The economics of the treatments have much importance in crop production that assess the most profitable treatment and determines the overall economic advantages of crop from practical point of view. Therefore, economics of different treatments were worked out in terms of cost of cultivation, gross monetary returns (GMR), net monetary returns (NMR) and benefit-cost ratio (B:C ratio) on per hectare area basis to ascertain the economic viability of the treatments.

\section{Cost of cultivation}

The cost of cultivation for each treatment was determined on the basis of the different operations and inputs used for raising the crop under different treatments.

\section{Gross monetary returns (GMR)}

The value received from the produce obtained under each treatment was computed on the 
basis of existing market price of produce. Total value of the produce was treated as gross monetary returns (GMR) per hectare under different treatments.

\section{Net monetary returns (NMR)}

The net monetary returns per hectare under different treatments were determined by subtracting the cost of cultivation of a particular treatment from the GMR of the same treatment.

\section{Benefit - cost ratio (B: C ratio)}

To estimate the benefits obtained from different treatments over each rupee of expenditure incurred, $\mathrm{B}: \mathrm{C}$ ratio of each treatment was calculated as per formula given below:

$\mathrm{B}: \mathrm{C}$ ratio $=$ Gross monetary returns per hectare / cost of cultivation per ha

\section{Results and Discussion}

\section{Effect on grain yields}

The grain yields of varieties are the final product for which varieties had been evolved (Table 4.9). Variety PS 3 with grain yields of $3525 \mathrm{~kg} / \mathrm{ha}$ excelled to all, but it was statistically comparable to PS 5, Danteshwari and Madhumati yielding $3450 \mathrm{~kg} / \mathrm{ha}, 3418$ $\mathrm{kg} / \mathrm{ha}$ and $3325 \mathrm{~kg} / \mathrm{ha}$ respectively. Grain yield of PS 3 was $2.13 \%$ higher than the yield of PS 5. Similarly, grain yield of PS 5 was $0.92 \%$ higher than the yield of Danteshwari. The next best varieties viz., IR 36, MTU 1010 and PS 4 were in descending order with the grain yields of $3350,3231,3120$ and 3010 $\mathrm{kg} / \mathrm{ha}$ respectively. These varieties had superior growth parameters and yield attributing characters as discussed earlier thus they produced significantly higher grain yields than others. BVD 109 was the lowest yielder with grain yield of $2563 \mathrm{~kg} / \mathrm{ha}$ among all varieties, but it was comparable to Pusa Basmati 1 (2620 kg/ha), Sahyadri (2740 $\mathrm{kg} / \mathrm{ha})$ and JR 201 (2793 kg/ha) in this regard. From the above facts, it could be concluded that several varieties evolved from different parts of the country viz. PS 3, PS 5 and Danteshwari were high yielder and Madhumati, IR 36, MTU 1010 and PS 4 were considerably good yielder under Jabalpur condition with organic nutrient management. The widely adopted fine and scented rice cv. Pusa Basmati 1 was lowest yielder among the scented varieties tested. These results were in close confirmity with the findings of Singh et al., (2007), Azad and Lehria (2001), Adhikari and Mishra (2004), Krishna Kumar et al., (2005) and G. Senthil Kumar et al., (2010).

\section{Effect on straw yields}

It is the biomass obtained after substracting the grain yields from total biological yields. Its productivity is directly related to the growth parameters viz. plant-height, tillers/hill, LAI of crop and consequently with the dry matter production/hill. Varieties significantly varied for straw yields (Table 4.9). Variety PS 3 produced maximum straw yields (5336 kg/ha) among all varieties, which was comparable to PS 5 (5310 kg/ha), BVD 109 (5239 kg/ha) and JR 201 (5216 kg/ha). These varieties had significant superiority in plant-height, tillers/hill and LAI than other varieties, hence they produced the higher straw yields. The straw yield was minimum (4676 kg/ha) under IR 36, which was at par to PS 4 (4726 kg/ha), MTU 1010 (4727 kg/ha), Pusa Basmati 1 (4784 kg/ha) and Madhumati (4843.33 kg/ha). The plant-height, tillers/hill, LAI and dry matter production/hill were minimum with these varieties which attributed to their lesser straw yields. Remaining varieties stood in intermediate position with regard to straw yields between above maximum and minimum yielding 
groups. These results were in close conformity with the findings of Singh et al., (2007), Azad and Lehria (2001), Adhikari and Mishra (2004), Krishna Kumar et al., (2005) and G. Senthil Kumar et al., (2010).

\section{Cost of cultivation}

Generally, the cost of cultivation of a crop under particular treatment varies according to market value of the variety. For determining the cost of cultivation under a particular treatment, variable and invariable cost of inputs and operations were taken into consideration. The cost of cultivation differed for scented and non-scented varieties because of higher price of scented seeds. The common inputs and operations between scented and non-scented rice varieties are variable cost of cultivation, while cost of seeds was the variable cost. To evaluate the total cost of cultivation, the cost involved for growing rice crop was taken into consideration in the present investigation. The common cost of cultivation for scented rice varieties were Rs 44168/ha and non-scented Rs 42508/ha. The cost of organic manures as well as charges of their application were high and full organic nutrient management required quite higher expenditure than integrated nutrient management. The cost of cultivation further increased, when scented seeds were used. The cost of cultivation under organic farming could be reduced, when organic manures would be prepared on the farm itself

\section{Gross monetary returns}

The GMR of different treatments varied remarkably. The GMR is, directly depend on the market price, the total monetary gain of the harvested produce. It was clear from the data that GMR was higher for scented varieties than non-scented varieties because scented varieties fetched more price. The GMR is the value of grain and straw yields from different varieties. Thus, it is directly related to the grain and straw yields of varieties. The GMR among scented rice varieties were maximum (Rs 111086/ha) with PS 3 closely followed by PS 5 (Rs 108810/ha), Madhumati (Rs 104593/ha). Among non-scented varieties were maximum (Rs 73296/ha) with Danteshwari closely followed by IR 36 (Rs 69296/ha), MTU 1010 (Rs 67127/ha), IR 64 (Rs 62150/ha). Though the grain and straw yields of Danteshwari was higher than other non-scented rice varieties. Varieties BVD 109, Sahyadri and JR 201 having lesser grain and straw yields and being non-scented, fetched the lesser (Rs 56499/ha, Rs 59890/ha and Rs 61076/ha respectively) GMR than other varieties. Rest of the varieties were in intermediate position for GMR.

Thus, it could be said that shifting from inorganic agriculture into organic agriculture may be more remunerative by growing high value crops. (Singh and Rai 2007)

\section{Net monetary returns}

The NMR is the actual monetary profit of a particular treatment, because it is determined by subtracting the cost of cultivation of a treatment from the GMR of the same treatment. The NMR of different treatments varied remarkably. The NMR of different varieties followed the same trend as of their GMR, because higher GMR gives the higher NMR with same cost of cultivation. Scented varieties fetched higher NMR as in case of their GMR. The NMR was maximum (Rs 67168/ha) with PS 3 closely followed by PS 5 (Rs 64642/ha) and Madhumati (Rs 60675/ha). 
Table.1 Economic analysis of different treatments on per hectare area basis

\begin{tabular}{|l|l|c|c|c|c|c|c|}
\hline T. No. & \multicolumn{1}{|c|}{ Treatments } & $\begin{array}{c}\text { Grain } \\
\text { yield } \\
\mathbf{k g} / \mathbf{h a})\end{array}$ & $\begin{array}{c}\text { Straw } \\
\text { yield } \\
\mathbf{( k g / h a})\end{array}$ & $\begin{array}{c}\text { Total } \\
\text { expenditu } \\
\text { re (Rs/ha) }\end{array}$ & $\begin{array}{c}\text { GMR } \\
\text { (Rs/ha) }\end{array}$ & $\begin{array}{c}\text { NMR } \\
\text { (Rs/ha) }\end{array}$ & $\begin{array}{c}\text { B:C } \\
\text { ratio }\end{array}$ \\
\hline $\mathbf{T}_{\mathbf{1}}$ & PS-5 & 3450 & 5310 & 44168 & 108810 & 64642 & 2.46 \\
\hline $\mathbf{T}_{\mathbf{2}}$ & SAHDARI & 2740 & 5090 & 42508 & 59890 & 17382 & 1.41 \\
\hline $\mathbf{T}_{\mathbf{3}}$ & PS-4 & 3010 & 4726 & 44168 & 95026 & 51108 & 2.16 \\
\hline $\mathbf{T}_{\mathbf{4}}$ & BVD-109 & 2563 & 5239 & 42508 & 56499 & 13991 & 1.33 \\
\hline $\mathbf{T}_{\mathbf{5}}$ & JR-201 & 2793 & 5216 & 42508 & 61076 & 18568 & 1.44 \\
\hline $\mathbf{T}_{\mathbf{6}}$ & DANTESHWARI & 3418 & 4936 & 42508 & 73296 & 30788 & 1.72 \\
\hline $\mathbf{T}_{\mathbf{7}}$ & MADHUMATI & 3325 & 4843 & 44168 & 104593 & 60675 & 2.38 \\
\hline $\mathbf{T}_{\mathbf{8}}$ & IR-36 & 3231 & 4676 & 42508 & 69296 & 26788 & 1.63 \\
\hline $\mathbf{T}_{\mathbf{9}}$ & MTU-1010 & 3120 & 4727 & 42508 & 67127 & 24619 & 1.58 \\
\hline $\mathbf{T}_{\mathbf{1 0}}$ & IR-64 & 2850 & 5150 & 42508 & 62150 & 19642 & 1.46 \\
\hline $\mathbf{T}_{\mathbf{1 1}}$ & Pusa Basmati 1 & 2620 & 4784 & 44168 & 83384 & 39466 & 1.90 \\
\hline $\mathbf{T}_{\mathbf{1 2}}$ & PS-3 & 3525 & 5336 & 44168 & 111086 & 67168 & 2.53 \\
\hline
\end{tabular}

Table.2 Cost of variable expenditure as per treatments Scented

\begin{tabular}{|c|l|c|c|}
\hline $\begin{array}{c}\text { Tr. } \\
\text { No. }\end{array}$ & Treatments & Quantity (Kg) & Cost (Rs) \\
\hline $\mathbf{T}_{\mathbf{1}}$ & PS 5 & 30 & 2400 \\
\hline $\mathbf{T}_{\mathbf{2}}$ & Sahyadri & 30 & 990 \\
\hline $\mathbf{T}_{\mathbf{3}}$ & PS 4 & 30 & 2400 \\
\hline $\mathbf{T}_{\mathbf{4}}$ & BVD 109 & 30 & 990 \\
\hline $\mathbf{T}_{\mathbf{5}}$ & JR 201 & 30 & 990 \\
\hline $\mathbf{T}_{\mathbf{6}}$ & Danteshwari & 30 & 990 \\
\hline $\mathbf{T}_{\mathbf{7}}$ & Madhumati & 30 & 2400 \\
\hline $\mathbf{T}_{\mathbf{8}}$ & IR 36 & 30 & 990 \\
\hline $\mathbf{T}_{\mathbf{9}}$ & MTU 1010 & 30 & 990 \\
\hline $\mathbf{T}_{\mathbf{1 0}}$ & IR 64 & 30 & 990 \\
\hline $\mathbf{T}_{\mathbf{1 1}}$ & Pusa Basmati 1 & 30 & 2400 \\
\hline $\mathbf{T}_{\mathbf{1 2}}$ & PS 3 & 30 & 2400 \\
\hline & seed cost- 80 Rs/kg, non-scented seed cost- 33 Rs/kg \\
\hline
\end{tabular}


Table.3 Total cost of cultivation (Rs/ha) as per treatment

\begin{tabular}{|c|c|c|c|}
\hline Tr. No. & $\begin{array}{c}\text { Cost of common } \\
\text { expenditure (Rs/ha) }\end{array}$ & $\begin{array}{c}\text { Cost of variable } \\
\text { expenditure (Rs/ha) }\end{array}$ & $\begin{array}{c}\text { Total cost of } \\
\text { cultivation (Rs/ha) }\end{array}$ \\
\hline $\mathbf{T}_{\mathbf{1}}$ & 41768 & 2400 & 44168 \\
\hline $\mathbf{T}_{\mathbf{2}}$ & 41518 & 990 & 42508 \\
\hline $\mathbf{T}_{\mathbf{3}}$ & 41768 & 2400 & 44168 \\
\hline $\mathbf{T}_{\mathbf{4}}$ & 41518 & 990 & 42508 \\
\hline $\mathbf{T}_{\mathbf{5}}$ & 41518 & 990 & 42508 \\
\hline $\mathbf{T}_{\mathbf{6}}$ & 41518 & 990 & 42508 \\
\hline $\mathbf{T}_{\mathbf{7}}$ & 41768 & 2400 & 44168 \\
\hline $\mathbf{T}_{\mathbf{8}}$ & 41518 & 990 & 42508 \\
\hline
\end{tabular}

Among non-scented varieties NMR were maximum (Rs 30788/ha) with Danteshwari closely followed by IR 36 (26788/ha). Varieties BVD 109 (Rs 13991/ha), Sahyadri (Rs 17382/ha) and JR 201 (Rs 18568/ha) fetched the minimum NMR among all the varieties. Rest of the varieties were in intermediate position for NMR ranging from Rs 39466/ha to Rs 19642/ha. (Pretty J. 2000) and (Ramesh et al., 2008)

\section{Benefit-cost ratio}

It is actual monetary profitability (gain), over each rupee of investment under a particular treatment. The B:C ratio was maximum (2.53) with the variety PS 3 closely followed by PS 5 (2.46) and Madhumati (Rs 2.38).Upadhyay et al., (2012)

It was minimum with BVD 109 (1.33), Sahyadri (1.41) and JR 201 (1.44). Rest of the varieties were in intermediate position for $\mathrm{B}: \mathrm{C}$ ratio ranging from 2.16 to 1.46 , which gave an indicative that organic farming in general, was not much remunerative. However, organic farming may be remunerative by producing organic manures on farm itself.

In conclusion, yielding ability of PS 3 was found superior with respect to grain and straw yields and productive and remunerative in terms of NMR Rs. 67168/ha with B:C ratio 2.53 closely followed by PS 5 (NMR Rs. 64642/ha with $\mathrm{B}: \mathrm{C}$ ratio 2.46) and Danteshwari.

\section{References}

Adhikari NP and Mishra BN. 2004. Effect of integrated sources of nitrogen on yield of aromatic rice and their residual effect on succeeding wheat crop. Annals of Agricultural Research 25(2): 327-328.

Anonymous. 2014. Agricultural and Processed Food Products Export Development

Authority.http://www.apeda.gov.in/aped awebsite/organic/Organic_Products.htm 1.

Azad BS and Lehria SK. 2001. Yield of rice through integrated nutrient management under irrigated conditions. Annals of Agricultural Research 22: 471-475.

Krishnakumar S, Saravanan S, Ramesh K, Natarajan SK and Mani S. 2005. Organic farming: Impact on rice (Oryza sativa L.) productivity and soil health. Asian Journal of Plant Sciences 4(5): 510-512.

Kumar A, Tripathi HP and Yadav DS. 2007. Correcting nutrients deficiency for sustainable crop production. Indian Journal of Fertilizers 2(11): 37-44.

Kumar GS, Shanmugam PM, Devasenapathy 
$\mathrm{P}$ and Vennila C. 2010. Productivity and Economics of Rice based cropping system as influenced by different organic manures. Agricultural Science Digest 30 (1): 69-70.

Pretty J. 2000. The real cost of modern farming. Agricultural systems 65: 113136.

Ramesh P, Panwar NR, Singh AB and Ramana S. 2008. Effect of organic manures on productivity, soil fertility and economics of soybean-durum wheat cropping system under organic farming in vertisols. Indian Journal of Agricultural Sciences 78(4): 351-354.

Singh RR and Rai B. 2007. Effect of chemical fertilizers, organic manures and soil amendments on production and economics of rice-wheat cropping system. Research on Crops 8 (3): 530532.

Singh YV, Singh BV, Pabbi S and Singh PK. 2007. Impact of organic farming on yield and quality of Basmati rice and soil properties. Paper present at Zwischen Tradition and globalisierung9, UniversitateHohenheim, Deutschland 20-23.03.07.

Upadhyay VB, Vishwakarma SK, Singh P and Soni M. 2012. Productivity and sustainability of rice (Oryza sativa) based cropping system in Kymore Plateau and Satpura hills zone of Madhya Pradesh. Indian journal of Agronomy 57(1): 8-13.

\section{How to cite this article:}

Khemraj Dubey, V.K. Shukla, Gajendra Raghuvansi, S.K. Vishwakarma and Muni Pratap Sahu. 2020. Evaluation of Economics in Different Rice Varieties for Organic Farming. Int.J.Curr.Microbiol.App.Sci. 9(06): 1937-1943. doi: https://doi.org/10.20546/ijcmas.2020.906.239 